\title{
AUTOMATED WAREHOUSE DESIGN USING VISUAL INTERACTIVE SIMULATION
}

\author{
António C. Brito \\ José A. Basto \\ Universidade do Porto, Faculdade de Engenharia, Departamento de Engenharia Mecânica e Gestão Industrial \\ Rua Dr. Roberto Frias; P-4200-465 PORTO; PORTUGAL \\ E-mail: acbrito@,fe.up.pt; jbbasto@fe.up.pt
}

\section{KEYWORDS}

Simulation, Modelling, Warehouse design

\section{ABSTRACT}

A simulation model of a full automated warehouse was custom developed for EFACEC, a large Portuguese company in the warehouse design, building and consultancy business. EFACEC was preparing a proposal for a client and they needed the model to evaluate and test their options. They also wanted to use the model as a marketing tool to gain the contract.

Two persons with previous experience in simulation formed the development team. The model was developed in four months with full time dedication, but was inflexible to support significant changes after EFACEC won the bid.

Furthermore, the increasing demand for warehouse design made the development of specific hard coded simulation models for EFACEC inadequate.

The need for a flexible tool, easier to use, lead to the development of a Decision Support System: AWARD (Advanced WARehouse Design).

\section{INTRODUCTION}

Computer simulation has become widely used in the analysis of complex problems and is now an important tool in decision making. Since the 1960s simulation has been used with success in solving real problems.

In 1976 the concept of Visual Interactive Simulation (VIS) was introduced by Hurrion (Hurrion 1976). With VIS a picture of the model running is displayed on the screen and the user can interrupt the model running, at any time, and interact with it in a way that he can influence the future behavior of the model.

Visual Interactive Simulation aggregates a set of graphics, visual and interactive techniques which can be incorporated with different levels of extension in a simulation system. In the past years, there have been a large number of situations where VIS was successfully applied to different areas, including warehousing as in (Crookes and Valentine 1982), (Dangelmaier and Bachers 1986), (Marín et al. 1998), (Feliz-Teixeira and Brito 1999), (Burnett and LeBaron 2001) and (Macro and Salmi 2002).
Warehouse design is a complex task and its success relies mainly on the designer's experience. The large number of technological options available and the difficulty in evaluating them justifies the search for better and more effective tools for warehouse design. The trend, in recent years, of building larger, automated warehousing systems has made warehouse design even more complex.

The nature of warehouse design requires the manipulation of large amounts of data and is often an iterative process that forces the designer to go through the different design phases several times before reaching the final solution. This suggests an integrated computer environment that can give support to the user during all the design phases.

\section{THE PROBLEM}

EFACEC's engineers had two design options that were identical except in the number of aisles and in the number of racking levels. The first option has six aisles with five levels of racking, and the second one has five aisles with seven levels of racking. In figure 1 the warehouse layout of the six aisle option is presented.

The warehouse must be capable of storing all the products coming from the different production plants and capable of supplying the company's retailers.

It has two bays at the reception and can unload simultaneously two trucks. The products arrive by truck in full pallets with 36 cases each. The pallets are unloaded automatically by roll conveyors, and then are transferred to a chain conveyor by a lift table.

One by one each pallet is moved by a rail trolley to another chain conveyor. During this path the pallet is identified by a bar code reader and has its overall dimensions automatically inspected.

If any problem is detected the pallet is directed to a different circuit (turn left in the end of the trolley path) for manual inspection. When the pallet is in good condition it is taken by the chain conveyor (on the right at the end of the trolley path) to another rail trolley.

This trolley moves the pallet to a chain conveyor on one of the racking aisles, according to the operational conditions. The pallet then waits in a table at the conveyor's end until it is picked up by the crane and put away in the racking. Each racking aisle has a dedicated crane. 


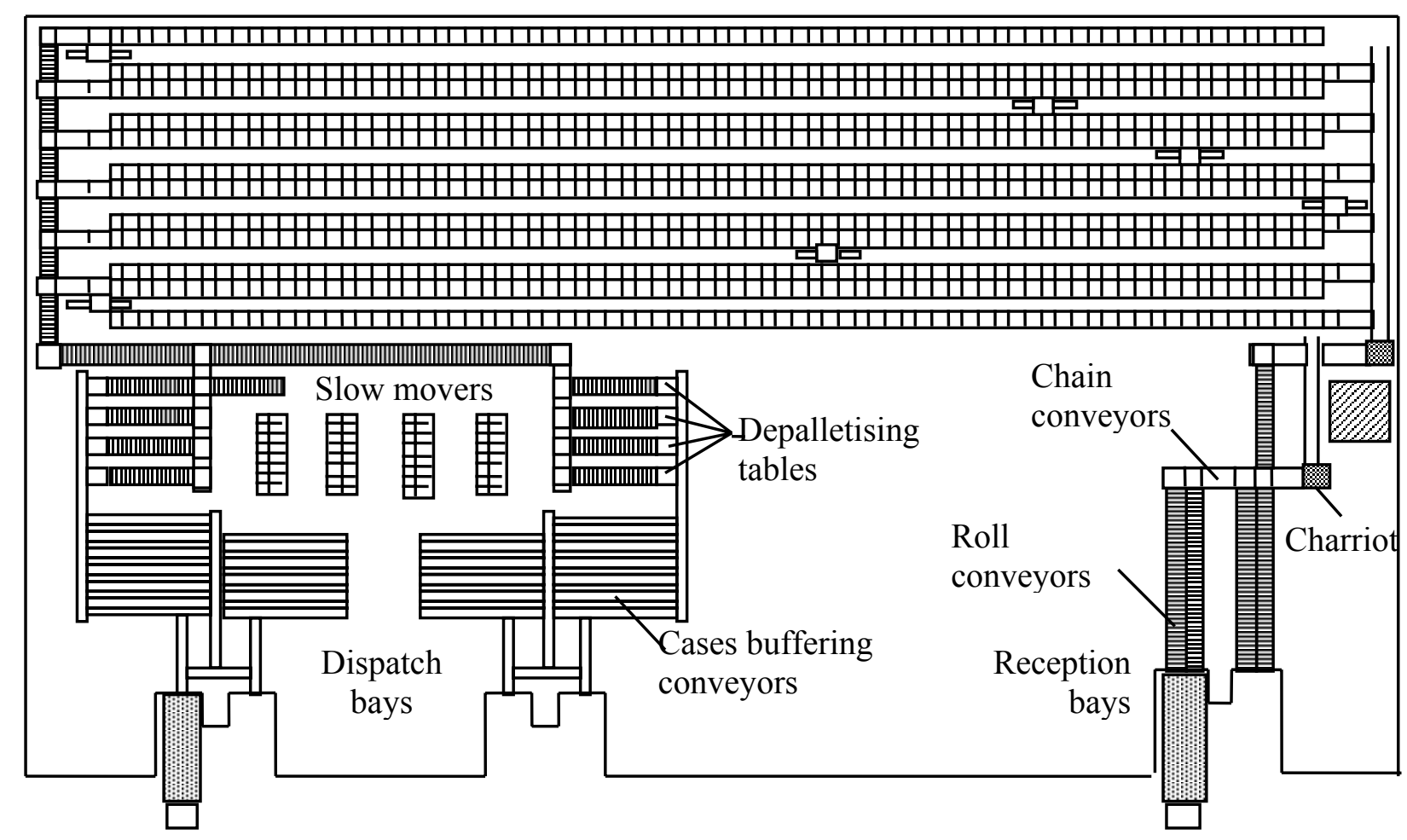

Figure 1: Fully automated warehouse layout

The warehouse has two identical dispatch docks (see fig. 1), each one with two bays.

Two trucks can be at the same time in one dock but only one can be loading. The existence of the two bays allows the preparation of one truck while the other one is loading. The product cases are loaded into the truck by conveyors. The loading sequence is defined by the computer according to the order information. As the truck must visit different company's retailers throughout the country the loading sequence must be made in the reverse order of the retailer's visit sequence to allow easy unloading.

The product cases daily throughput is very high and diversified as this warehouse serves as central distribution point for retailers throughout Portugal.

To cope with loading peak times and to prevent cases shortage EFACEC's engineers have designed a solution consisting of a set of cases buffering conveyors and depalletising tables (see fig. 1). The computer controls the opening of each buffering conveyor, according to the order's item list, allowing the cases to flow to the main conveyor and be loaded to the truck at a very high rate. When there is enough space in the buffering conveyors a pallet is automatically depalletised. Its cases are directed by a conveyor to the buffering conveyors that need to be replenished.

The depalletising tables are fed by a conveyor that accumulates pallets acting as a buffer. When a pallet is needed in this area the computer issues an order to the racking cranes that pick up the required pallet. The pallet is then taken to the depalletising area by the conveyor system. The depalletising tables and buffering conveyors are dedicated to certain products. The decision was taken according to the products throughput rate.

There are a total of thirty products. The demand is stable and seasonal effects are not significant. The Pareto analysis of the daily throughput shows that $20 \%$ of the products are responsible for $90 \%$ of the throughput.

The products are grouped in five classes according to the daily throughput. Table 1 presents the class boundaries and the number of products in each class.

The twelve case buffering conveyors are dedicated to classes 1 and 2 . Two case buffering conveyors and a depalletising table are dedicated to each product in class 1. One case buffering conveyor is dedicated to each product in class 2 and one depalletising table is dedicated to the whole class. Four conveyors and one depalletising table are left out for future expansion or to be used in the case of a break down.

Table 1: The Product Classes in the EFACEC's Warehouse

\begin{tabular}{|c||c||c|}
\hline Class & Daily Throughput (cases) & $\mathrm{N}^{\mathrm{o}}$ of products \\
\hline \hline 1 & $>1000$ & 2 \\
\hline 2 & $>250$ & 4 \\
\hline 3 & $>34$ & 6 \\
\hline 4 & $>17$ & 6 \\
\hline 5 & $\leq 17$ & 12 \\
\hline
\end{tabular}

The ten case buffering conveyors set is dedicated to classes 3, 4 and 5. One conveyor is dedicated to each product from class 3 . The products from class 4 and 5 use two conveyors. Two conveyors are left out for 
future expansion or to be used in the case of a break down. The order's items for products in class 4 and 5 are prepared manually in advance and placed in the corresponding conveyor.

Products in classes 3,4 and 5 are picked from the slow movers racking (see figure 1) and are handled manually due to its low rotation. The slow movers racking is replenished whenever a pallet is emptied. An order is issued to the racking cranes and the pallet is picked from the main racking and taken by the conveyor system to the slow movers zone. A transporter picks up the pallet at the conveyor end and puts it away in the racking.

The pallets are picked in the main racking using the FIFO (First In First Out) rule. This rule is used to prevent the products from being stored for long periods of time that could lead to deterioration. When the rail trolley has a pallet ready to be taken to the racking the computer must decide to which aisle the pallet should go. The objective is to balance the number of product pallets in each aisle. The pallet is taken to the aisle which has the smallest number of pallets from that product. In each aisle the pallet is put away in the free cell that is nearest the aisle exit.

In the two EFACEC design options all the warehouse parameters are the same except the number of aisles and the racking dimensions. Table 2 shows the different parameters used in each option.

Table 2: The Number of Aisles, Levels and Racking Cells in the Two Design Options

\begin{tabular}{|c||c||c||c||c|}
\hline Option & $\mathrm{N}^{\circ}$ of aisles & $\begin{array}{c}\mathrm{N}^{\circ} \text { of pallets } \\
\text { / level / aisle }\end{array}$ & $\mathrm{N}^{\circ}$ of levels & $\mathrm{N}^{\circ}$ of cells \\
\hline \hline 1 & 6 & 156 & 5 & 4680 \\
\hline 2 & 5 & 132 & 7 & 4620 \\
\hline
\end{tabular}

The inorders and outorders profile are well known by EFACEC's client. The products arrive to the warehouse in trucks coming from the company production plants. The profile of outorders is defined based on the current distribution data.

\section{SIMULATION MODEL}

A Visual Interactive Simulation model was developed to evaluate EFACEC's design options. The model uses the SIMVIS libraries and utilities described in (Bastos and Moreira da Silva 1985).

This simulation library was written at the Management Group (GEIN) of the Mechanical Engineering and Industrial Management Department (DEMEGI) of the Faculty of Engineering - Porto University - Portugal. The programming language used was FORTRAN and later $\mathrm{C}++$. The library is based on the simulation event approach.

Although SIMVIS was used to build simulation models, its main objective was the development of Data-Driven Generic Models. The SIMVIS author's strategy was to conceive a system with the basic tools necessary to support the development of model generators for specific domains. With the Data-Driven Generic Models the user can build models with a friendly interface using a dialogue that he can understand and without a great need of simulation expertise. A set of support libraries were also developed, at GEIN, to allow the software to be easily ported to other operating systems or be adapted to work with different graphics terminals. This was achieved by building separate libraries for the low level $\mathrm{I} / \mathrm{O}$ and graphics modules, that are device and/or operating system dependent, and for the high level I/O and simulation modules, that are device and operating system independent. Each simulation model is defined by programming the events and all the user interaction and graphics display animation.

The development of the warehouse simulation model had the following objectives:

- to evaluate the warehouse overall performance;

- to verify whether the dispatch bays and the cases buffering conveyor system were able to load the expected trucks in the required time and without delays;

- to verify if the depalletising tables and the pallets replenishing system were sufficient to supply the cases buffering conveyors without breaking the case loading flow;

- to establish the minimum number of racking cranes capable of doing the pallet storage and replenishment operations without bottle-necks;

- to convince the client of the quality of EFACEC's proposal;

- to be used as a competitive edge against competitors.

A scaled design, similar to the one from figure 1 , is used to display the running of the simulation model. The pallets movement on the conveyors, the movement of the trolleys and racking cranes are realistic displayed. The individual pallets whilst being transported are represented by a scaled square which is drawing using the product colour code. When the pallets are stored in the racking cell they are represented by a line segment with the same colour.

After the depalletisation (because of scale) it is not possible to do a detailed display of the cases flow. This flow is represented by a line which connects the table with the destination conveyor. The same technique is used to represent the case flow between the buffering conveyor and the truck being loaded. The colour and position of the line is updated every time a change occurs. An icon representation is used to show the trucks at the bays or waiting to get in.

The model structure is composed of three modules. The configuration module allows, for the layout of figure 1 , the definition of the coordinates, the number of aisles and the number of racking levels. In the IDUMP module the user is asked to define the start date and time and the duration of the simulation. Next it generates the internal simulation model structure.

The simulation module allows the running of any previously defined configuration. 

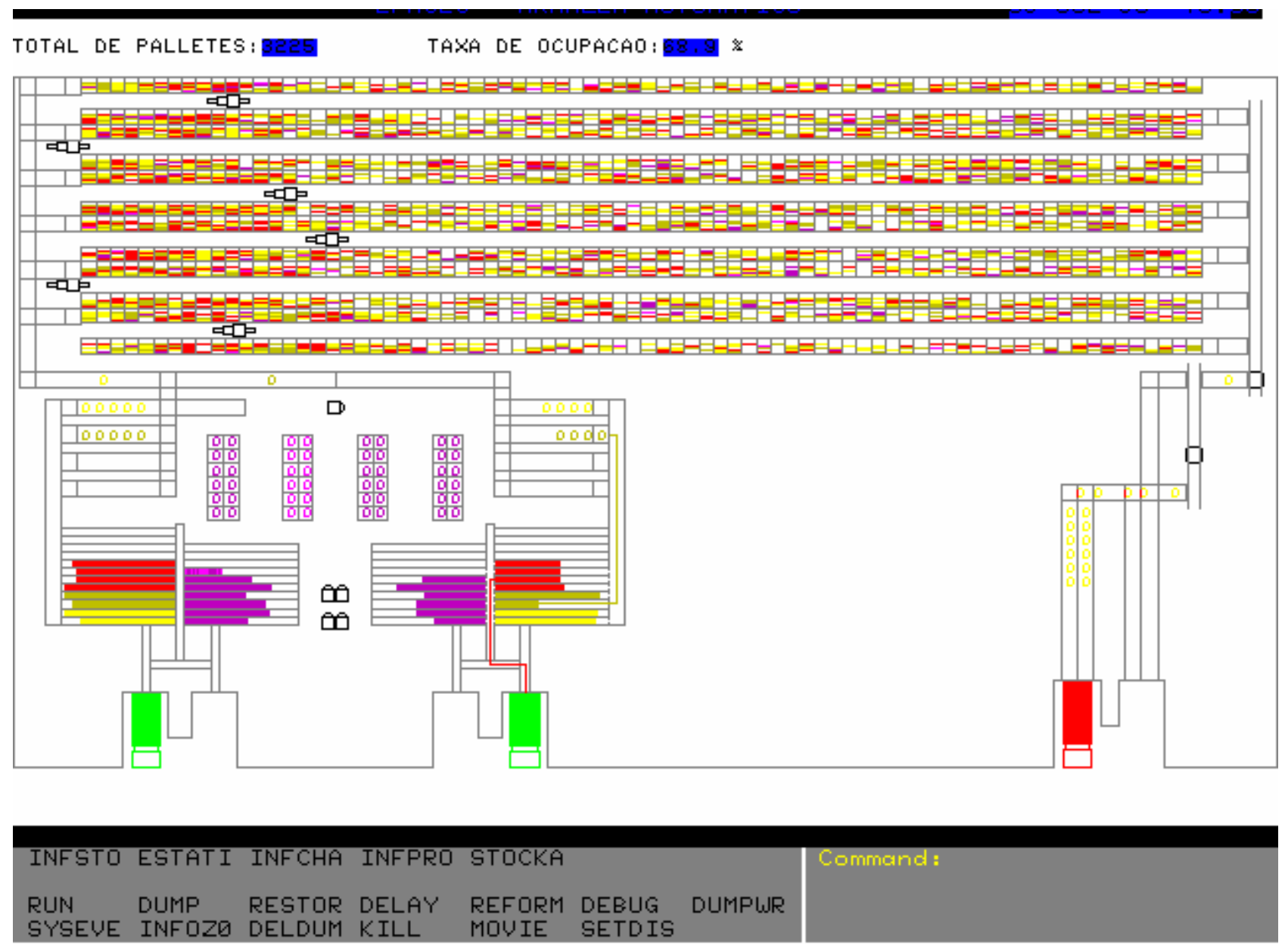

Figure 2: Screen Display during the Running of the "EFACEC" Model

Figure 2 shows a picture of the display during the running of the simulation model. The running of the simulation can be interrupted at any time and the user can execute several SIMVIS commands called system interactions. The user can also execute any of the following commands developed specifically for this model and called user interactions:

- $\quad$ INFSTO - transporters histogram statistics;

- $\quad$ ESTATI - current warehouse state data;

- $\quad$ INFCHA - trolleys histogram statistics;

- $\quad$ INFPRO - histogram of the $n^{\circ}$ of pallets for each product / all products;

- $\quad$ STOCK - change the transporters' control logic.

The STOCK interaction allows the user to change at any time the transporters' control logic. Any of the following rules can be defined for each one of the racking cranes:

- $\quad$ STORE - do only pallet storage operations;

- $\quad$ PICK - do only pallet picking operations;

- $\quad$ STO/PIC - do both pallet storage and picking operations giving higher priority to the picking operations;

- $\quad$ BREAK - do nothing (breakdown situation).
The warehouse simulation model was developed specifically for the evaluation of EFACEC's design options. Nevertheless new warehouse simulation elements were created that can be used in other situations. The modeling of conveyors is a good example.

\section{RESULTS}

The objectives described in 2. for the development of the EFACEC's simulation model were achieved. The running of the simulation model has given a thorough understanding of the warehouse design options.

A major objective was to decide between design options 1 and 2 (see table 2). As the crane cost is high the option 2 was preferable. The question was to know if five cranes were enough to do the job. The simulation study of a typical 8 hours shift showed that five cranes were capable of doing the pallet storage and replenishment operations without delays. Figure 3 presents the cranes statistics for a 4,5 and 6 aisles options in an 8 hours shift. 


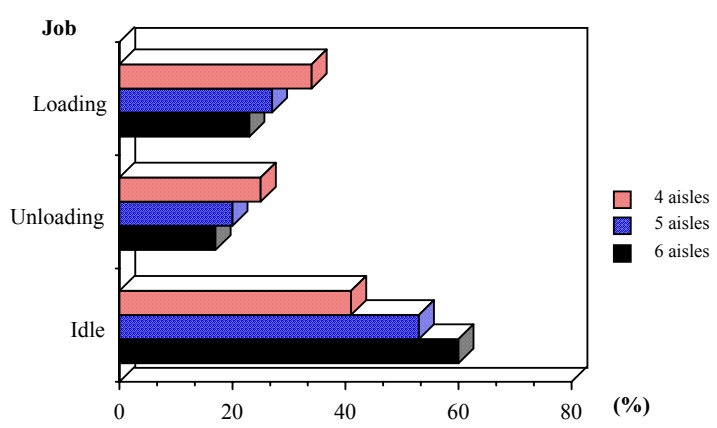

Figure 3: Cranes Operational statistics ( $\%$ of simulation time)

As it is necessary to allow for a crane to be stopped for maintenance without affecting the pallet replenishment operations the four crane option was also analyzed. The simulation results showed that five cranes are sufficient for the replenishment operations with allowances for maintenance and future increase in the demand.

The simulation study has also demonstrated that the dispatch bays and the case buffering conveyor system are capable of loading the expected trucks in the required time and without delays. A truck waiting to be loaded queue was never formed.

The depalletising tables and the pallets replenishment system have proved to be effective. Under normal working conditions the trucks loading cases flow was never interrupted by cases shortage. The simulation analysis of the warehouse overall performance was fully satisfactory.

The model was also used to explain the solution to EFACEC's client and to convince him of the merit of the project. The scaled animation and the quality of the graphics display have caused a great impact in the client. The fact that EFACEC was the only company to use simulation to evaluate the project was used as a competitive edge against competitors. The simulation project was fully successful.

\section{CRITICAL ISSUES}

Two persons with previous experience in simulation formed the development team. The model was developed in four months with full time dedication. EFACEC's engineers have given warehouse technical support and helped in the model validation.

Although the simulation project was considered successful by everyone, its approach has revealed some limitations. EFACEC has gained the contract and later on there was a need to do significant changes in the initial warehouse configuration. EFACEC wanted these modifications to be included in the simulation model in order to be evaluated. Unfortunately the required time to do it and its cost made the solution unacceptable for EFACEC.

Furthermore, the increasing demand for warehouse design made the development of specific simulation models for EFACEC inadequate. The limited number of simulation experts and the required development time made this approach impractical. EFACEC knew that simulation was crucial in warehouse design but it has no internal expertise and people to do it. So other alternatives had to be looked for.

\section{CONCLUSIONS}

\subsection{Alternatives for Warehouse Simulation}

When a warehouse simulation model has to be developed two options can be made: use a consultant or simulation expert; or develop the model within the warehouse management or design team.

The use of a consultant or simulation expert can speed up the process of obtaining results and gives professional expertise. However, this option is usually more expensive and most of the time does not have the flexibility required. Also, communication problems can arise between the simulation expert and the warehouse team. The simulation expert is not aware of warehouse problems and the warehouse team have difficulties in understanding some technical aspects of the simulation. These difficulties are a major drawback and can compromise the success of simulation projects.

Furthermore, with the growing need of simulation models in warehousing it is not possible to find always a simulation expert available to do the job. The development of the simulation model within the warehouse team appears so to be the most desirable solution. The question is: how appropriate current simulation systems are to be used by people from the warehouse business to develop warehouse models?

For a simulation system to be effectively used by warehouse designers it must have a user friendly interface, a warehousing specific terminology and it must be easy to use and enable the development of simulation models in short periods of time. From all the different simulation approaches described, the most adequate to provide these characteristics is the Datadriven Generic Model approach.

Manufacturing and warehousing systems have some similarities. The existing manufacturing simulation systems can sometimes be used to build warehouse models. However common elements such as transporters or storage units have different contributions for the global efficiency of manufacturing and warehousing systems. Movement is the prime activity in a warehouse; machining processing is the prime activity in a production unit.

The current simulation systems that could be used by warehouse business people are not appropriate to simulate warehouses. To model the complex logic of a warehouse system a programming or simulation language has to be used. For that, expertise in simulation and programming are required. This kind of expertise is not common to find within warehouse business people and the increasing need for warehouse simulation makes each time more difficult to find external consultants to do the job. In either case the development of dedicated warehouse simulation models 
is very time consuming and does not have the flexibility required.

The Data-driven Generic Models approach is the right one to allow warehouse designers to build simulation models. However current simulation systems using this approach are not appropriate for warehouse simulation. Warehouse systems have special characteristics that require a new way of defining the simulation model and new modeling elements to represent its complex logic.

\subsection{Design Brief}

In manufacturing systems machine working is the centre of activity and transport and storage are auxiliary activities. In manufacturing systems job processing times and scheduling rules must be modelled accurately while travel times can be taken approximately, storage access logic simplified and physical locations ignored.

In warehousing systems movement is the centre of activity. The system performance depends mainly on the efficiency of the storage and picking operations which in turn depends on the speed in which pallets are moved, picked and put away. As movement is the prime activity in a warehouse: storage physical locations, travel paths, transporters' speed must be rigorously modelled. This explains why current manufacturing simulation systems are not appropriate for warehouse simulation.

Physical locations and travel distances are crucial in warehouse modelling. The warehouse layout is a key factor in the success of the system. When developing warehouse models the spatial factor is essential for a good representation of the real system.

A warehousing simulation system using the Datadriven Generic Model approach should then have the following characteristics:

- a user friendly interface using warehouse terminology;

- an effective way of defining the physical layout in order to enable the model of movement with the required level of accuracy;

- simulation elements which allow a correct modelling of warehouse logic.

An example of this approach is AWARD (Advanced WARehouse Design), a software package to support warehouse design and management. AWARD development has been user oriented and incorporates the experience and background discussed above, as described in (Brito and Basto 1992).

\section{REFERENCES}

Bastos, J. M. and C. Moreira da Silva. 1985 "SIMVIS: A Visual Interactive General Purpose Simulation System", Progress Report no 2, Universidade do Porto, Faculdade de Engenharia, Departamento de Engenharia Mecânica, Portugal.

Brito, A.C. and J. Basto. 1992, "The Use of Computer Aided Design Techniques in Configuring Visual Interactive Simulation Models for Warehouse Design", Revue des Systèmes de Décision, v 1, n 2-3, p 191 - 212

Burnett, D. and T. LeBaron, 2001, "Efficiently modeling warehouse systems" in Proceedings of the 2001 Winter Simulation Conference (Arlington, VA, Dec 912), IEEE, Picataway, NJ, p 1001-1006

Crookes, J. G. and B. Valentine, 1982, "Simulation in MicroComputers", J. Opl. Res. Soc., 33, 855-858,..

Dangelmaier, W. and R. Bachers, 1986 "SIMULAP - A Simulation System For Material Flow and Warehouse Design", Material Flow, n 3, p 207-214.

Feliz-Teixeira, J.M., A.C. Brito. 1999, "Visual C++ Software for Warehouse Simulation". In Proceedings of the 11th European Simulation Symposium (Erlangen, Oct 24-27), Germany, p 181-186.

Hurrion, R., "The Design, Use and Requirements of an Interactive Visual Computer Simulation Language to Explore Production Planning Problems", Ph.D. thesis, University of London, 1976.

Macro, J. and R. Salmi, 2002, "A simulation tool to determine warehouse efficiencies and storage allocations" in Proceedings of the 2002 Winter Simulation Conference (San Diego, CA, Dec 8-11), IEEE, Picataway, NJ, p 1274-1281

Marín, R.M.; J. Garrido, J.L. Trillo, J. Saez, J. Armesto. 1998 "Design and simulation of an industrial automated overhead warehouse" Integrated Manufacturing Systems, v 9, n 5-6, p 308-313.

\section{AUTHOR BIOGRAPHIES}

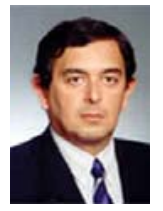

ANTÓNIO C. BRITO was born in Porto, Portugal and went to Universidade do Porto, where he studied mechanical engineering and obtained his degree in 1981, staying in the same institution as Lecturer where he did his M.S. thesis in 1985. He obtained his Ph.D. in Simulation from the School of Management at the University of Cranfield (U.K.) in 1993. He is Auxiliar Professor at Universidade do Porto since 1993, where he leads research in the field of Visual Interactive Simulation. His e-mail address is: acbrito@,fe.up.pt

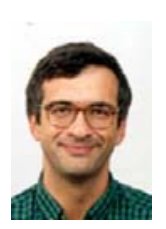

JOSÉ A. BASTO was born in Porto, Portugal and went to Universidade do Porto, where he studied mechanical engineering and obtained his degree in 1986, staying in the same institution as Lecturer. $\mathrm{He}$ obtained his Ph.D. in Industrial Engineering from Lehigh University (U.S.A.) in 2001. He is Auxiliar Professor at Universidade do Porto since 2001, where he leads research in the field of Flexible Manufacturing. His e-mail address is: jbbasto@fe.up.pt 